\title{
Brugada ECG pattern: a physiopathological prospective study based on clinical, electrophysiological, angiographic, and genetic findings
}

\author{
Guillaume Duthoit ${ }^{1 *}$, Véronique Fressart ${ }^{2}$, Françoise Hidden-Lucet ${ }^{1}$, Françoise Simon ${ }^{2}$, \\ Darouna Kattygnarath ${ }^{3}$, Philippe Charron ${ }^{4}$, Caroline Himbert ${ }^{1}$, Philip Aouate ${ }^{5}$, Pascale Guicheney ${ }^{3}$, \\ Yves Lecarpentier ${ }^{6}{ }^{6}$ Robert Frank ${ }^{1}$ and Jean-Louis Hébert ${ }^{6}$
}

1 Unité de Rythmologie, Institut de Cardiologie, GHU Pitié-Salpêtrière, Paris, France

${ }^{2}$ UF de Cardiogénétique et Myogénétique, GHU Pitié-Salpêtrière, Paris, France

${ }^{3}$ Faculté de Médecine Pierre et Marie Curie, Inserm-UPMC UMR S 956, Paris, France

${ }^{4}$ Département de Génétique, GHU Pitié-Salpêtrière, Paris, France

${ }^{5}$ Service de Cardiologie, Hôpital Laënnec, Creil, France

${ }^{6}$ Service de Physiologie Cardiorespiratoire, CHU de Bicêtre, Le Kremlin-Bicêtre, France

Edited by:

Ruben Coronel, Academic Medical Center, Netherlands

\section{Reviewed by:}

Ruben Coronel, Academic Medical Center, Netherlands

George E. Billman, The Ohio State University, USA

*Correspondence:

Guillaume Duthoit, Unité de Rythmologie, Institut de Cardiologie, Hôpital Pitié-Salpêtrière, APHP,

47-83 Boulevard de l'Hôpital,

75013 Paris, France.

e-mail: guillaume.duthoit@ psl.aphp.fr
Introduction: Brugada syndrome $(\mathrm{BrS})$ is considered a primary electrical disease. However, morphological abnormalities have been reported and localized arrhythmogenic right ventricular (RV) dysplasia/cardiomyopathy (ARVD/C) may mimic its phenotype, raising the question of an overlap between these two conditions and making difficult the therapeutic management of patients with borderline forms. The main objective of this study was to assess prospectively the prevalence of $\mathrm{BrS}$ and $\mathrm{ARVD} / \mathrm{C}$ on the basis of international criteria, in patients with BrS-ECG and normal echocardiography, looking for a potential overlap between the two pathologies. The secondary objectives were to describe and quantify angiographic structural alterations, hemodynamics, electrophysiology, and genetics in the setting of BrS-ECG. Materials and Methods: Hundred and fourteen consecutive patients matched in age underwent prospectively cardiac catheterization and quantitative biventricular contrast angiography to rule out a structural heart disease. Fifty-one patients with a BrS-ECG (BrS group, 7F, 44 M, $43 \pm 11$ y) had a spontaneous or ajmaline-induced BrS coved type ECG. For angiographic comparison, 49 patients with localized ARVD/C but without ST segment elevation in the right precordial leads $(14 \mathrm{~F}, 35 \mathrm{M}, 39 \pm 13 \mathrm{y})$ were also studied. They fulfilled international ESCNHF 2000 criteria and presented angiographic localized forms, mainly confined to hypokinetic anteroapical zone (characterized by trabecular dysarray and hypertrophy), and/or diaphragmatic wall, thus resulting in RV normal volumes and preserved systolic function. These two populations were also compared with 14 control patients $(7 \mathrm{~F}, 7 \mathrm{M}, 38 \pm 16 \mathrm{y})$. Among $\mathrm{BrS}$ group, we identified three main angiographic phenotypes: BrS group I = patients with normal RV $(n=15,29 \%)$; BrS group $\|=$ patients with segmental RV wall motion abnormalities but no structural arguments for ARVD/C ( $n=26,51 \%)$; BrS group III = patients with localized abnormalities suggestive of focal ARVD/C ( $n=10,20 \%)$. Results: Among BrS group, 34/51 patients (67\%) fulfilled BrS HRS/EHRA 2005 criteria. Nineteen (37\%) were symptomatic for aborted sudden death, agonal nocturnal respiration or syncope. Ventricular stimulation was positive in 14 patients (28\%). Angiography showed RV abnormalities in 36/51 patients (71\%) of BrS group (BrS groups II and III). Late potentials were present in $73 \%(100 \%$ sensitivity and NPV for an angiographic ARVD/C, but poor specificity and PPV, both $37 \%$ ). In $\mathrm{BrS}$ group III, $8 / 10$ patients (16\% of $\mathrm{BrS}$ patients) finally fulfilled international ESCNHF 2000 ARVD/C criteria and 5/10 (10\% of BrS patients) fulfilled $\mathrm{BrS}$ diagnostic criteria. An overlap was observed in 4 patients ( $8 \%$ of $\mathrm{BrS}$ patients) who fulfilled both $\mathrm{ARVD} / \mathrm{C}$ and $\mathrm{BrS}$ criteria. Among the 45 genotyped patients, only one presented a SCN5A mutation, whereas a TRPM4 mutation was found in another patient. Both belonged to BrS group II. MOG1 gene analysis was negative for all patients, as were PKP2, DSP, DSG2, and DSC2 analyzes performed in BrS group III. Conclusions: Seventy-one percent of patients with a BrS-ECG had abnormal RV wall motion and $16 \%$ 
had structural alterations corresponding to localized (anteroapical and/or diaphragmatic) ARVD/C. Moreover, 8\% of BrS-ECG patients fulfilled both BrS and ARVD/C criteria. Our results support the hypothesis of an overlap between BrS and localized forms of ARVD/C. Conversely, genetic screening was poorly contributive for both diseases in the present series.

Keywords: Brugada syndrome, arrhythmogenic right ventricular cardiomyopathy, overlap, contrast angiography, genetic testing

\section{INTRODUCTION}

Brugada syndrome (BrS) predisposes to an increased risk of sudden cardiac death (SCD) due to ventricular fibrillation (VF) in apparently normal hearts (Brugada and Brugada, 1992). Its diagnostic criteria have been described in the second consensus conference (Wilde et al., 2002; Antzelevitch et al., 2005), where experts emphasized the need for exclusion of an organic heart disease, particularly an arrhythmogenic right ventricular (RV) dysplasia/cardiomyopathy (ARVD/C), before establishing the diagnosis of BrS. However, morphological assessment has been limited to echocardiography in most studies and has not been yet codified. Moreover, several authors showed evidence for structural, dynamic (Martini et al., 1989; Takagi et al., 2001; Papavassiliu et al., 2004), and histological (Martini et al., 1989; Corrado et al., 1996, 2001; Frustaci et al., 2005) RV abnormalities in patients with typical BrS. Brugada ECG pattern (BrSECG) indeed has been unmasked by ajmaline drug-challenge in $16 \%$ of $55 \mathrm{ARVD} / \mathrm{C}$ patients (Peters et al., 2004), and several authors made the hypothesis of an overlap between $\mathrm{BrS}$ and ARVD/C (Perez Riera et al., 2005), raising the difficult question of therapeutic management of patients with borderline forms. Two recent publications (Frustaci et al., 2005; Kim et al., 2006) showed that the "BrS" phenotype was not specific of one disease but could be the result of early, i.e., localized, organic abnormalities, underdiagnosed by echocardiography or MRI but revealed by invasive contrast angiography (microaneurysms or ARVD/C) or by endomyocardial biopsies (myocarditis, ARVD/C, cardiomyopathy).

On one hand, SCN5A mutation accounts for only $15-25 \%$ of patients with BrS (Ackerman et al., 2011), with an autosomal dominant inheritance (Chen et al., 1998). Other mutations have been described but appear mostly private and HRS/EHRA guidelines only recommend to restrict genetic testing to SCN5A in BrS (Ackerman et al., 2011). On the other hand, six genes $(P K P 2=$ plakophillin-2, DSP $=$ desmoplakin, $D S G 2=$ desmoglein $-2, J U P=$ junctional plakoglobin, $T G F \beta 3=$ Transforming Growth Factor- $\beta 3, R y R 2=$ cardiac Ryanodin Receptor-2) and 12 loci have been identified in ARVD/C so far,

\footnotetext{
Abbreviations: BrS, Brugada Syndrome; BrS-ECG, Brugada Syndrome ECG pattern; SCD, Sudden Cardiac Death; VF, Ventricular Fibrillation; ARVD/C, Arrhythmogenic Right Ventricular Dysplasia/Cardiomyopathy; RV/LV, Right/Left Ventricle; PPV/NPV, Positive/Negative Predictive Values; RAO/LAO, Right/Left Anterior Oblique (projection); EF, Ejection Fraction; TAPSE, Tricuspid Annulus Plane Systolic Excursion; SA-ECG, Signal Averaged-Electrocardiogram; PVS, Programmed Ventricular Stimulation; RVOT, Right Ventricular Outflow Tract; VT, Ventricular Tachycardia; MRI, Magnetic Resonance Imaging; $\mathrm{EDV}_{\mathrm{i}} / \mathrm{ESV}_{\mathrm{i}}$, End Diastolic Volume index/End Systolic Volume index; SI, Stroke Index.
}

accounting for 30-70\% of cases (Basso et al., 2006; Corrado and Thiene, 2006; Pilichou et al., 2006; Van Tintelen et al., 2006; Sen-Chowdhry et al., 2007a,b), with an autosomal dominant inheritance in half of cases (Hamid et al., 2002) and with a tropism for desmosomal proteins.

The main objective of the present study was to look for a potential overlap between $\mathrm{BrS}$ and $\mathrm{ARVD} / \mathrm{C}$ by assessing prospectively the prevalence of these two pathologies in patients presenting in daily practice with a typical BrS-ECG and a normal echocardiography. For this purpose, we used international criteria (HRS/EHRA 2005 criteria for BrS; ESC/WHF 2000 criteria for ARVD/C) (McKenna et al., 1994; Corrado et al., 2000; Antzelevitch et al., 2005) and quantitative contrast angiography of the RV which is considered a gold standard for ARVD/C diagnosis, particularly in localized forms (Hébert et al., 2004). The secondary objectives were to describe and quantify angiographic structural alterations, hemodynamics, electrophysiology, and genetics in the setting of BrS-ECG.

\section{MATERIALS AND METHODS STUDY POPULATION}

We conducted a prospective and monocentric study involving 114 patients who were matched in age and consecutively explored in our catheterization laboratory from April 2001 to July 2006 to rule out a structural heart disease. Invasive studies were performed after having obtained the written consent of each patient.

The population under study comprised two groups of patients and a control group: First, 51 patients (BrS group) were included because of a type 1 (coved-type) BrS-ECG, either spontaneously ( $n=19)$ or during ajmaline test (performed in 41 patients), according to the criteria defined in the second consensus conference report (Antzelevitch et al., 2005). They had also a normal echocardiography. Second, 49 consecutive patients with localized ARVD/C and without ST segment elevation in the right precordial leads were also studied for angiographic comparison. All fulfilled ESC/WHF 2000 criteria for ARVD/C (McKenna et al., 1994; Corrado et al., 2000) and presented angiographic localized forms, mainly confined to hypokinetic anteroapical zone (characterized by trabecular dysarray and hypertrophy), and/or diaphragmatic wall, thus resulting in RV normal volumes and preserved systolic function [particularly RVEF $\geq 35 \%$ and tricuspid annulus plane systolic excursion (TAPSE) $\geq 14 \mathrm{~mm}$ ]. Third, these two populations were compared with 14 control patients matched in age and consecutively recruited during the same period.

Among BrS group, we identified three main phenotypes (Figure 1): (1) BrS group I (or "pure" BrS) corresponding to 


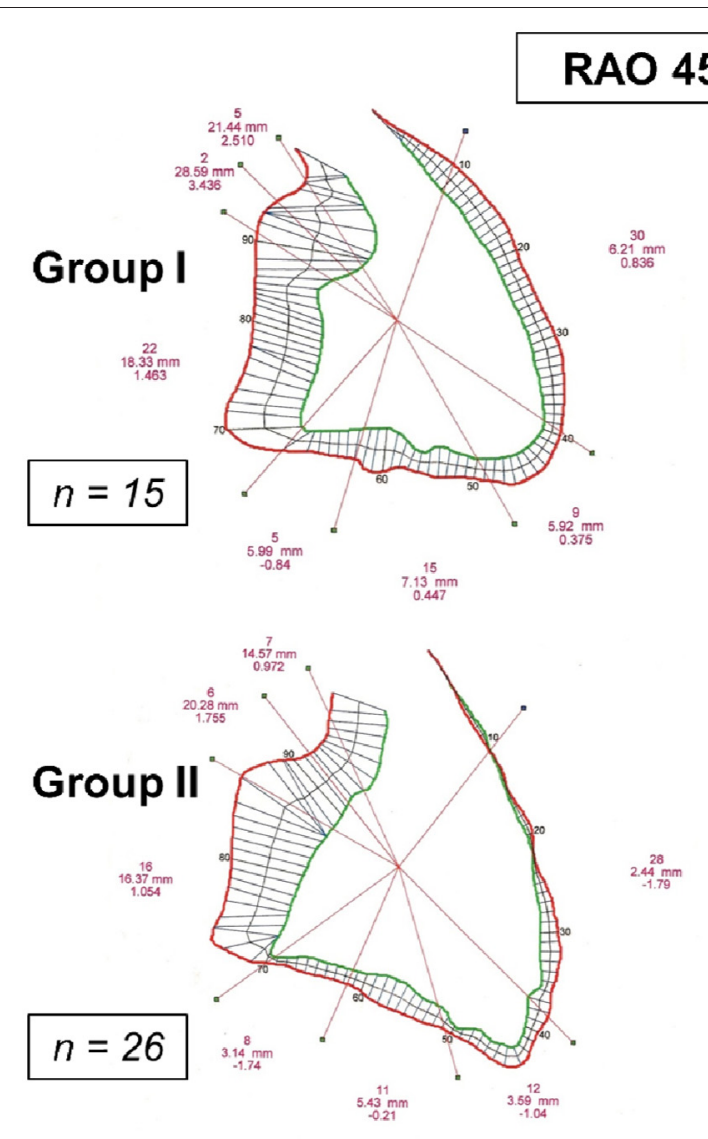

FIGURE 1 | Right ventricular (RV) angiographic contours in a $45^{\circ}$ right anterior oblique (RAO $45^{\circ}$ ) projection and cineangiographic classification of BrS group, according to qualitative analysis of image-recordings and to quantitative analysis of right ventricular segmental excursion analysis. BrS group I: normal RV (patient 32); BrS group II: patients with BrS-ECG and segmental RV wall motion abnormalities but without arguments for ARVD/C (patient 40: anterior RV akinesia, apical, inferior and subtricuspid hypokinesia, normal TAPSE, and crista supraventricularis shortening); and BrS group III: patients with BrS-ECG and angiographic abnormalities compatible with ARVD/C (patient 42: anteroapical akinesia, trabecular disarray and hypertrophy, end systolic polycyclic images). For each contour, the segmental excursions between diastole and systole are expressed in purple characters (from top to bottom: number of analyzed chords for each segment; mean segmental excursion in $\mathrm{mm}$; standard deviation from normal). patients with BrS-ECG with strictly normal RV; (2) BrS group II corresponding to patients with BrS-ECG and segmental RV wall motion abnormalities but without arguments for ARVD/C; and (3) BrS group III corresponding to patients with BrSECG and angiographic structural abnormalities compatible with ARVD/C. For all of them, underlying structural cardiac abnormalities had been excluded previously by physical examination, chest X-ray, 2-dimensional echocardiography, and by stress-ECG when appropriate. All patients had normal serum $\left[\mathrm{K}^{+}\right]$and $\left[\mathrm{Ca}^{2+}\right]$, troponin $\mathrm{I}_{\mathrm{c}}, \mathrm{C}$-Reactive Protein, and $\mathrm{TSH}_{\mathrm{us}}$ at the time of diagnosis.

Control patients ( 7 females, 7 males) had been explored consecutively during the same period without medication in our unit for atypical chest pain associated with a modified stress-ECG (10 patients) or persistant suspicion of pulmonary embolism despite normal scintigraphy, finally excluded by pulmonary contrast angiography (4 patients). All had normal pressures, RV and LV volumes and coronary angiograms. Quantitative data concerning their hemodynamics and segmental excursion were used to define normal values and reference nomograms for segmental excursion [in both $45^{\circ}$ right anterior oblique (RAO) and left anterior oblique (LAO) projections for each ventricle].

Ajmaline was administered under careful monitoring $(1 \mathrm{mg} / \mathrm{kg}$ body weight, at a rate of $1 \mathrm{mg} / \mathrm{s}$ with a maximal dose of $100 \mathrm{mg}$ ). Patients were excluded if a QRS widening $\geq 30 \%$ occurred even associated with a coved-type ECG, unless the type 1 pattern remained present in two right precordial leads $\left(\mathrm{V}_{1}, \mathrm{~V}_{2}\right.$, or $\left.\mathrm{V}_{3}\right)$ after QRS width normalization. All patients actually received a dose of $1 \mathrm{mg} / \mathrm{kg}$ of ajmaline. At the rate of $1 \mathrm{mg} / \mathrm{s}$, conduction slowing and/or ventricular proarrhythmic effect appear in our experience between 2 and 4 min after starting the infusion and never before $90 \mathrm{~s}$. This means that the full dose of ajmaline ( $\max$ $100 \mathrm{mg}$ ) is actually given when its effects begin on ECG.

A proband was defined as the first case of Brugada ECG diagnosed within the family. Familial history of SCD, BrS, or ARVD/C was defined accordingly to international criteria (McKenna et al., 1994; Antzelevitch et al., 2005). Family history of BrS was defined by the presence of one of the following findings documented at 
the time of inclusion: sudden cardiac death of a first degree relative under the age of 45 years; documented coved-type ECG in family members (spontaneous or induced).

\section{ELECTROPHYSIOLOGY (BrS GROUP)}

Thirty-seven patients underwent signal-averaged ECG (SA-ECG, high-pass filter of $25 \mathrm{~Hz}$ and/or $40 \mathrm{~Hz}$, low-pass filter of $250 \mathrm{~Hz}$ ). Ventricular late potentials were defined by the presence of $\geq 2$ of the 3 ESC/AHA/ACC criteria (filtered QRS $>114 \mathrm{~ms}$ at 40 and $25 \mathrm{~Hz}$; LAS > $38 \mathrm{~ms}$ at $40 \mathrm{~Hz}$, LAS $\geq 32 \mathrm{~ms}$ at $25 \mathrm{~Hz}$; RMS40 < $20 \mu \mathrm{V}$ at $40 \mathrm{~Hz}, \mathrm{RMS} 40 \leq 25 \mu \mathrm{V}$ at $25 \mathrm{~Hz}$ ) (Gomes et al., 1987; Breithardt et al., 1991).

Electrophysiological study, performed in all but one patient $(n=50)$, included basal measurement of HV interval $(n=36)$ and programmed ventricular stimulation (PVS, $n=50$ ) without antiarrhythmic drugs. PVS had to be performed after angiography during the same hospitalization, or at least one month before angiography to avoid functional wall motion abnormalities due to fast pacing or recent electrical cardioversion. PVS was applied at two sites [apex and RV outflow tract (RVOT)], at two drive cycle lengths (600 and $400 \mathrm{~ms}$ ), using a maximum of three extrastimuli with a minimum coupling interval of $200 \mathrm{~ms}$. Patients were inducible if a sustained (>30s) or syncopal ventricular arrhythmia occurred [VF, polymorphic ventricular tachycardia (VT), or monomorphic VT (Priori et al., 2002; Antzelevitch et al., 2005)].

\section{NON-INVASIVE IMAGING (BrS GROUP)}

Among BrS group, all included patients had normal 2dimensional echocardiography. Mean LVEF was $64 \pm 5 \%$ in BrS group. Moreover, 32 patients underwent biventricular phase angioscintigraphy and 29 patients underwent cardiac magnetic resonance imaging (MRI).

\section{CARDIAC CATHETERIZATION}

All patients underwent right and left heart catheterization, and coronary angiography performed by the same operator. Fluidfilled pressures and pulmonary artery thermodilution cardiac output were assessed (Swan-Ganz catheter, Abbott, Chicago, Illinois). RV angiography was performed through a $145^{\circ} 6 \mathrm{~F}$ angled pigtail catheter positioned at the RV apex, beyond the moderator band. Left heart catheterization was performed through a straight $6 \mathrm{~F}$ pigtail catheter (Cordis, Roden, The Netherlands). All patients had normal coronary angiograms.

RV and LV cineangiograms were recorded using two successive orthogonal views ( $\mathrm{RAO} 45^{\circ}$ and $\mathrm{LAO} 45^{\circ}$ without angulation). We chose these specific projections for better measurement of TAPSE and crista supraventricularis shortening in the RAO projection and septal morphology in LAO projection, whatever RV dilation (Hébert et al., 2004). Image calibration used a $40 \mathrm{~mm}$ metal ball. Images were analyzed by two independent trained cardiologists (JLH, GD) using dedicated software (Philips Research Laboratory, Suresnes, France).

Based on ESC/WHF 2000 criteria (Marcus et al., 1982; McKenna et al., 1994; Corrado et al., 2000) and Hébert et al. work (Hébert et al., 2004), RV structural abnormalities were defined by hypertrophic trabeculae $\geq 4 \mathrm{~mm}$ ("deep fissuring" of the anterior wall), areas of negative contrast in the trabecular zone and/or the moderator band (polycyclic images), apical aneurysm often associated with Y-shaped negative contrast image, large bulging or multiple outpouchings of the diaphragmatic wall, diastolic bulging of the subtricuspid area, RVOT aneurysm as well as RV free wall bulging in $\mathrm{LAO}$ projection.

Biventricular segmental motion was assessed by a modified quantitative Sheehan centerline method (Hébert et al., 2004) (100 clockwise chords, segmental shortening expressed in $\mathrm{mm}$ in both projections). For each projection, segmentation of RV and LV was manually performed and corresponded to a welldefined anatomical zone (Figures 1, 2, 4). The mean excursion was then automatically averaged for each segment and expressed in millimeters \pm one standard deviation (SD), and transposed on a comparative nomogram for each projection, showing individual chord shortening compared to mean values (mean $\pm 1 \mathrm{SD}$ ) obtained in control patients (Figure 2). Biplane volume calculations $(\mathrm{mL})$ were performed according to Boak's hemielliptical model for the RV, and to Dodge's ellipsoidal model for the LV (Hébert et al., 2004).

\section{GENETIC ANALYSIS}

DNA was extracted from peripheral blood lymphocytes according to standard procedures, after having obtained the written consent of the patients. SCN5A gene analysis was performed in 35 patients from BrS groups I and II (without ARVD/C). All BrS group III patients underwent a more extensive genetic study, which comprised analysis of SCN5A but also of genes coding for desmosomal proteins, including PKP2, DSP, DSG2, and DSC2. We did not analyze $R y R 2$, JUP, and TGFB3 with respect to the clinical presentation of the patients (absence of catecholaminergic VT or palmo-plantar hyperkeratosis), and because of the controversial role of $R y R 2$ in the pathogenesis of ARVD/C.

As MOG1 (Multi-copy suppressor Of GSP1 mutants) was recently described as a partner of $\mathrm{Na}(\mathrm{v}) 1.5$, playing a potential role in the regulation of its expression and trafficking (Kattygnarath et al., 2011), we decided to study the prevalence of MOG1 mutation in our population. Mutations in the TRPM4 gene (Transient Receptor Potential channel (type 4) belonging to the Melastatin subfamily). TRP channels have been identified as a cause of an autosomal dominant form of cardiac conduction disease. As BrS patients or relatives often present with conduction disturbances (atrio-ventricular block, sick sinus syndrome, fascicular block), we decided at the time of the study to consider also TRPM4 as a candidate gene for BrS (Stallmeyer et al., 2012).

All coding exons of the genes SCN5A, MOG1, TRPM4 and PKP2, DSP, DSG2, DSC2 were amplified by polymerase chain reaction (PCR) with specific primers and directly sequenced in both strands. Direct sequencing was performed with the use of the Big Dye dideoxy-terminator chemistry (Perkin Elmer) on ABI 3830 DNA sequencer (PE Applied Biosystems, Foster, CA). A mutation was defined by the presence of an abnormal variant which has not been described in previously published series, which was absent in a panel of 300 controls (600 alleles) and which was located in a highly conserved region through animal species. When available, cosegregation within the family was considered as the last clue to confirm a mutation. 
A

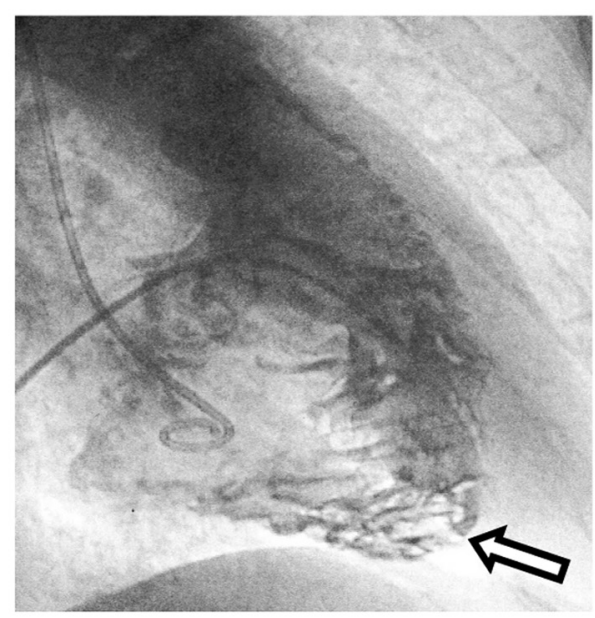

C

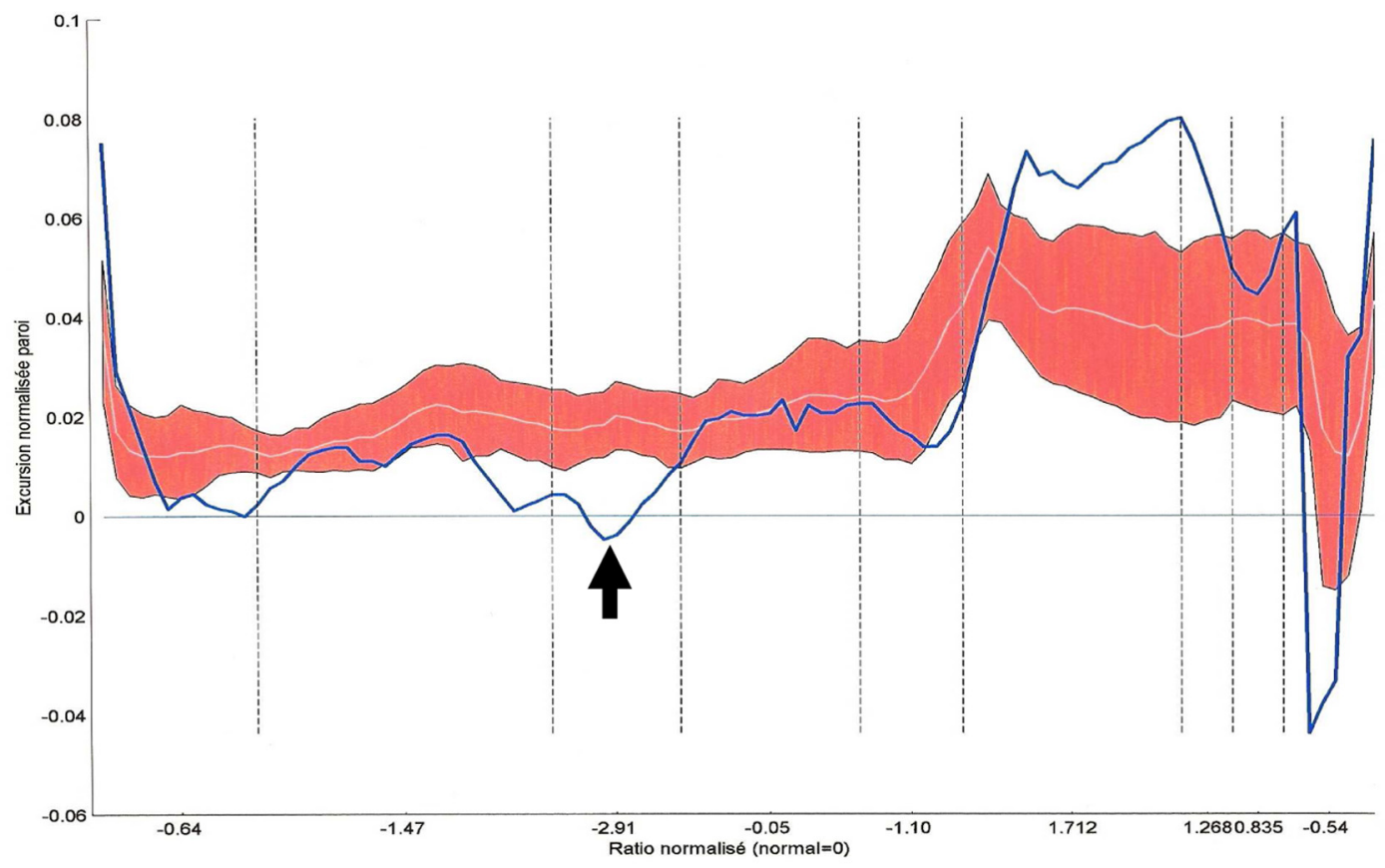

FIGURE 2 | Quantitative angiographic analysis of segmental right ventricular (RV) excursions in a $45^{\circ}$ right anterior oblique projection (patient 43, BrS group III, ARVD/C with BrS-ECG). (A) RV cineangiogram at end diastole: trabecular hypertrophy $(>4 \mathrm{~mm})$ and disarray which is predominant at the apical part of the RV (white arrow). (B) RV end diastolic (red) and end systolic (green) contours showing an akinetic

infundibulotrabecular junction (i.e., high RVOT), a hypokinetic anterior wall, a
B

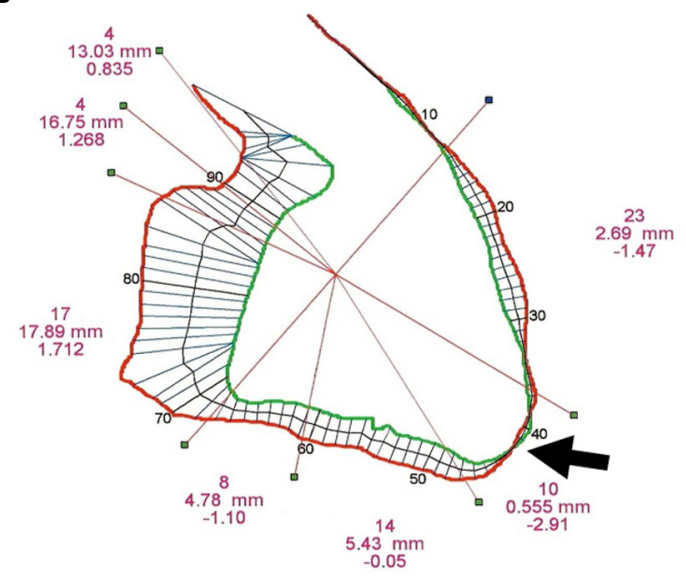

dyskinetic apex (black arrow), a normal inferior contraction and a hypokinetic sub-tricuspid segment. TAPSE, RV volumes, and RVEF were normal. (C) Segmental excursions are plotted (blue line, bold) on a nomogram in a clockwise direction from the high RVOT to the TAPSE and the crista supraventricularis. Normal excursion values are represented by the red zone (the white line represents the mean values of control patients and the red zone corresponds to $+1 \mathrm{SD}$ or $-1 \mathrm{SD}$ ).

\section{STATISTICAL ANALYSIS}

Quantitative data are expressed as mean \pm SD and percentages. We used a Student's unpaired $t$-test for comparison of quantitative data and an exact Fischer's test for percentages. For multiple comparisons we performed a variance analysis (ANOVA), followed by a Student's unpaired $t$-test, and balanced by the Bonferroni correction. Qualitative data were compared using $\chi^{2}$ test. A $p$-value $<0.05$ was considered significant.

\section{RESULTS}

\section{POPULATION}

We included 51 patients in the BrS group ( 7 females, 44 males, mean age $43 \pm 11$ years), 49 patients with localized ARVD/C and no ST-segment elevation in the right precordial leads (14 females, 35 males, mean age $39 \pm 13$ years), and 14 control patients ( 7 females, 7 males, mean age $38 \pm 16$ years). The main results regarding the $\mathrm{BrS}$ group population are summarized in Tables 1, 2. Sex ratio M/F was significantly higher in the BrS 


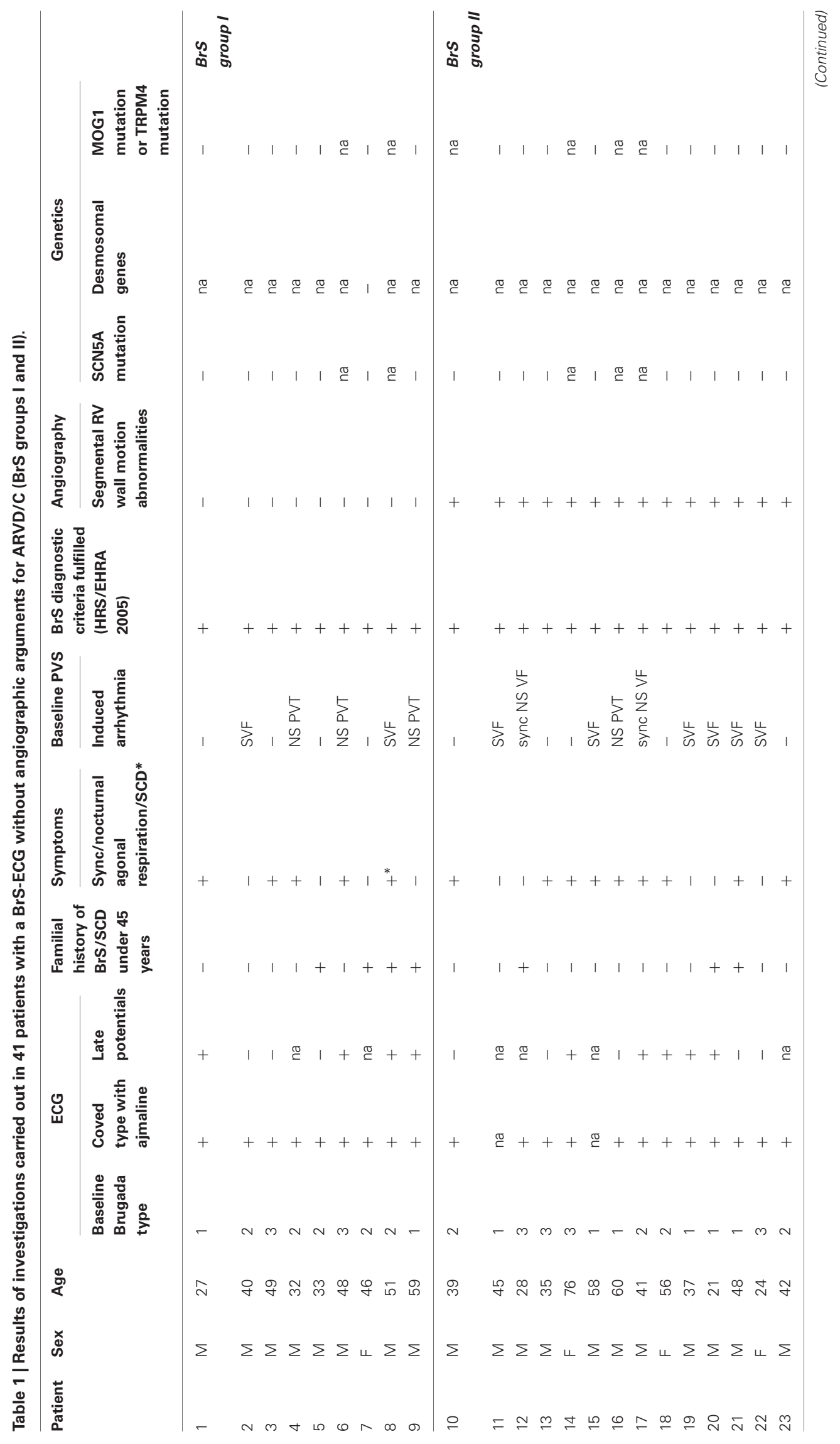




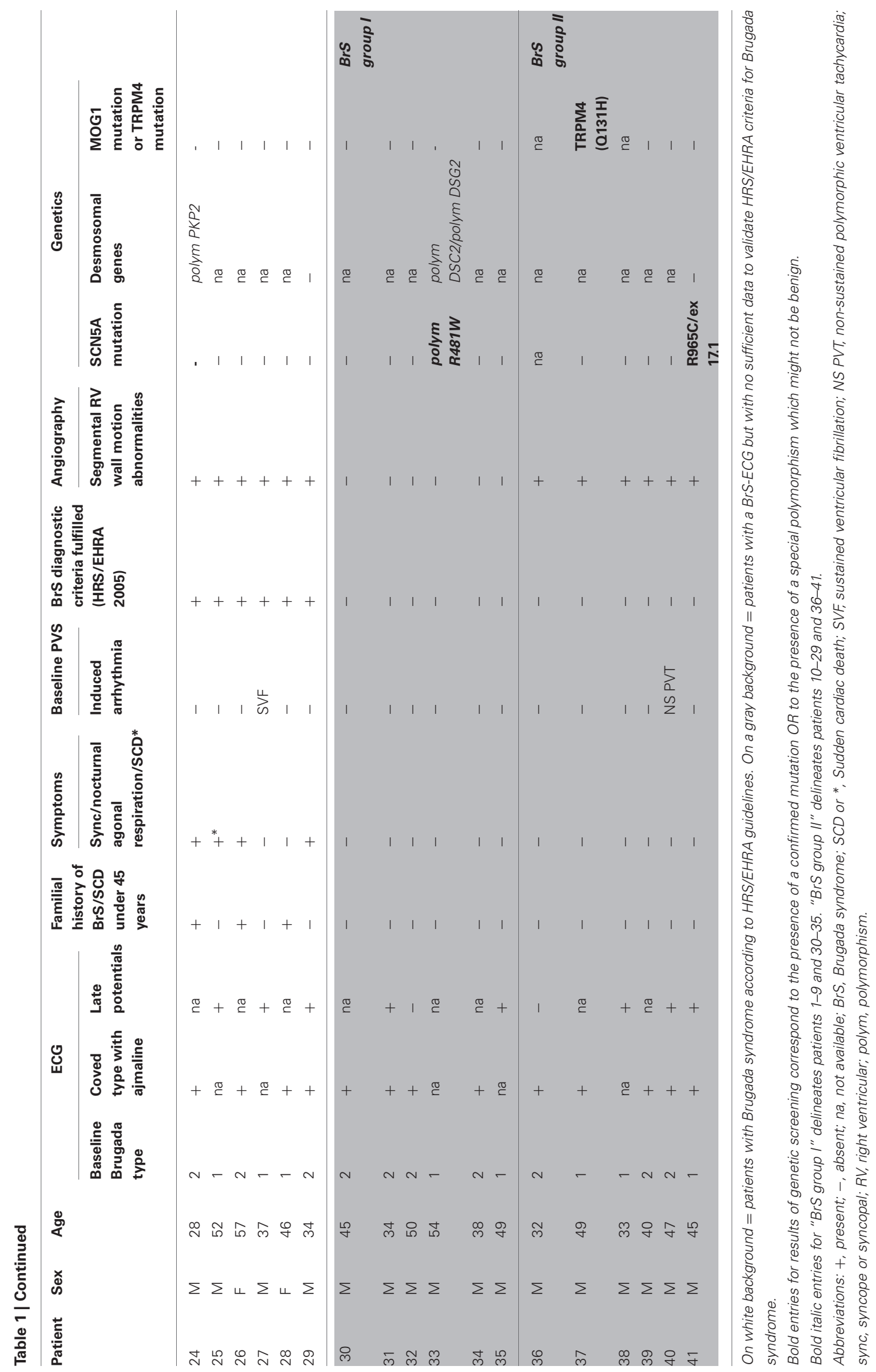




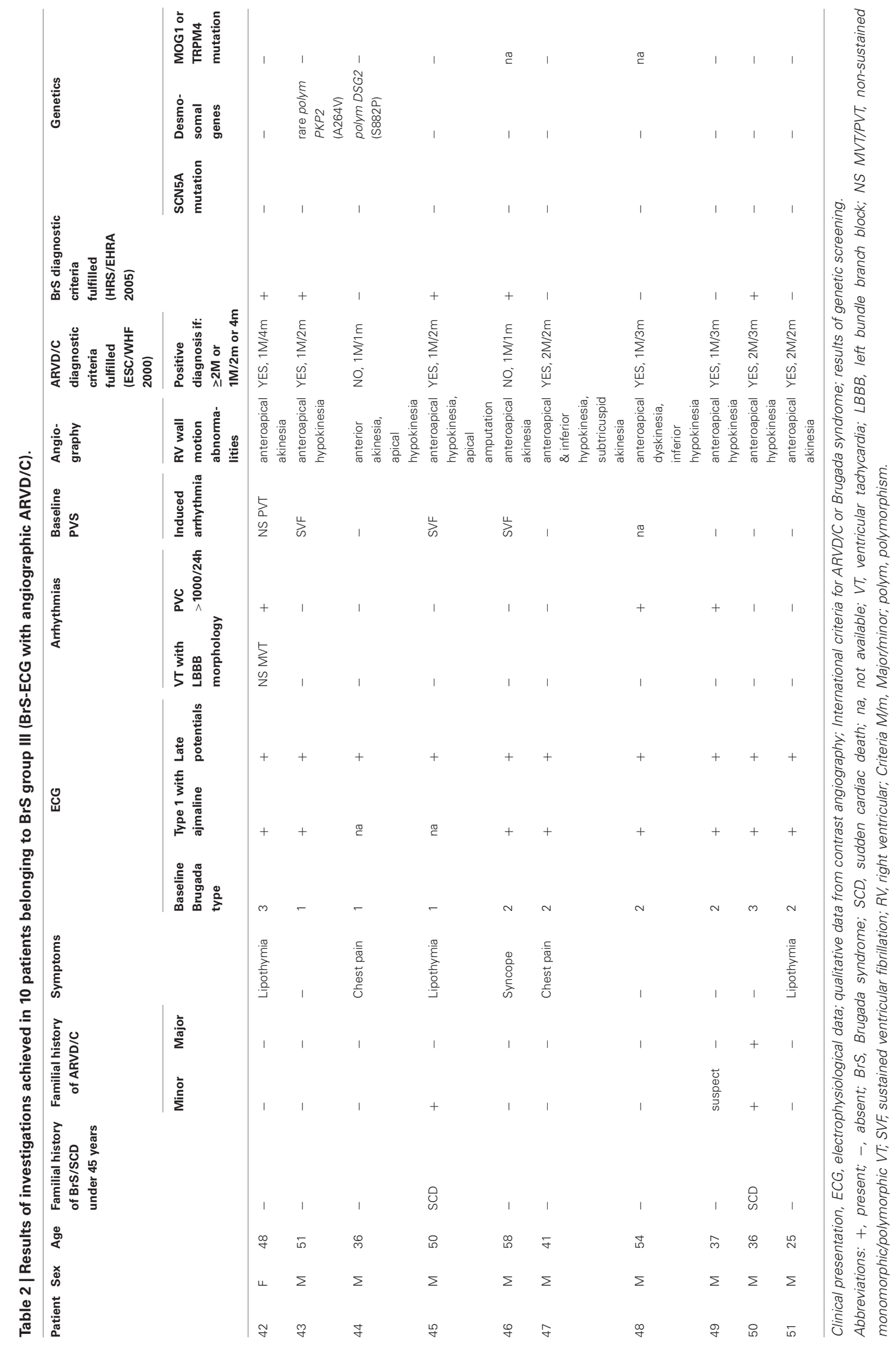


group compared to patients with localized ARVD/C without ST abnormalities and to control patients (respectively 6.3 vs. 2.5 and $1, p=0.0001$, Table 3 ). This difference remained significant when comparing localized ARVD/C without ST abnormalities, either with a BS population pooling together $\mathrm{BrS}$ group I and $\mathrm{BrS}$ group II (i.e., BrS-ECG and no ARVD/C) or with the BrS group III (sex ratios M/F respectively of 2.5 vs. 5.8 and $9, p=0.0001$ ).

Among BrS group, 19/51 patients (37\%) presented with a spontaneous BrS type 1 ECG. The remaining 32 had a baseline BrS type 2 or 3 ECG, converted to type 1 under ajmaline infusion. Familial screening of BrS concerned only 5 patients of our series, whereas the remaining 46 were probands. Nineteen patients $(37 \%)$ were symptomatic for aborted sudden death, agonal nocturnal respiration or syncope. Two patients presented with aborted SCD (documented nocturnal VF), 2 others with nocturnal seizures and syncope history, and 15 with at least one syncopal episode. Among patients without aborted sudden death, agonal nocturnal respiration or syncope, 2 patients presented palpitations and dizziness, 6 complained of lipothymia, and 5 others of palpitations. Remarkably, 12/34 patients (24\%) had atypical chest pain, which was the cause of achieving an ECG in 10 patients. For the remaining 9 asymptomatic patients (18\%), BrS-ECG diagnosis was fortuitous (systematic ECG). At the time of inclusion, 3 patients had an ICD because of type 1 ECG associated with history of aborted SCD, nocturnal agonal respiration or syncope. There was no statistical difference in terms of symptoms (syncope, SCD, seizures) between patients regarding the BrS-ECG type $(1,2$, or 3$)(p=0.5)$. Moreover, no statistical significant difference was observed between BrS groups I, II, and III, in terms of symptoms (atypical chest pain, syncope or pre-syncope, seizures, SCD, $p=0.08)$.

\section{PRIMARY OUTCOME (TABLES 1, 2)}

Among BrS group, 34/51 patients (67\%) fulfilled BrS HRS/EHRA 2005 criteria (Antzelevitch et al., 2005), mainly because 19/51 (37\%) were symptomatic with aborted sudden death, agonal nocturnal respiration or syncope, because of a positive ventricular stimulation in 14 patients $(28 \%)$ or because of a familial history of SCD before the age of 45 years in 10 patients (20\%). Among BrS group III, $8 / 10$ patients (16\% of all the BrS-ECGs) fulfilled international ESC/WHF 2000 ARVD/C criteria (McKenna et al., 1994; Corrado et al., 2000) and 5/10 (10\% of all the BrS-ECGs) fulfilled BrS HRS/EHRA 2005 diagnostic criteria. An overlap was observed in 4 patients ( $8 \%$ of all the BrS-ECGs) who fulfilled both $\mathrm{ARVD} / \mathrm{C}$ and $\mathrm{BrS}$ international criteria.

\section{NON-INVASIVE ELECTROPHYSIOLOGY (BrS GROUP)}

Systematic ECG recording in one upper space above the usual right precordial leads (3rd intercostal space for $\mathrm{V}_{1 H}$ ( $\mathrm{V}_{1}$ "high") and $\mathrm{V}_{2 H}$, 4th intercostal space for $\mathrm{V}_{3 \mathrm{H}}$ ) showed a BrS type 1 ECG in $63 \%$ of the cases $(n=26$, Figure 3$)$ and allowed the diagnosis of BrS-ECG in $34 \%$ ( $n=14$, where a coved-type pattern was only visible in one of the classical leads $\mathrm{V}_{1}, \mathrm{~V}_{2}, \mathrm{~V}_{3}$, but also in one or more of the leads $\left.\mathrm{V}_{1 \mathrm{H}}, \mathrm{V}_{2 \mathrm{H}}, \mathrm{V}_{3 \mathrm{H}}\right)$. Reversible conduction slowing was observed in $24 \%$ of the cases $(n=10$, mainly PR interval and QRS duration (>30\%) prolongation). No further complication occurred.
Baseline ECG showed a prolonged PR interval ( $\geq 200 \mathrm{~ms}$ ) in 7 patients (14\%), a left anterior fascicular block (QRS axis beneath $\left.-30^{\circ}\right)$ in 7 patients $(14 \%)$ and a left posterior fascicular block in one patient (patient 28, BrS group II, with a PR interval of $200 \mathrm{~ms}$ ). Remarkably, a left anterior fascicular block was present in 2 patients with ARVC/D (BrS group III) as compared to 5 patients $(p=N S)$ without ARVD/C [BrS (I+II) groups]. A prolonged PR interval alone was present in 2 patients with ARVD/C (BrS group III) and in 4 patients without ARVD/C [BrS group $(\mathrm{I}+\mathrm{II}), p=N S]$.

Holter-ECG or continuous monitoring showed premature ventricular contractions in $12 / 51$ patients (24\%), with a left bundle branch block pattern in 9, and associated with non-sustained RVOT tachycardia in one patient from BrS group III $(n=42)$.

SA-ECG was performed in 37/51 patients from BrS group (73\%) at 40 and/or $25 \mathrm{~Hz}$. When combining the results of SAECG at 40 and/or $25 \mathrm{~Hz}$, late potentials were present in 27 patients out of $37(73 \%)$. The presence of late potentials (at 40 and/or $25 \mathrm{~Hz}$ ) was associated with a sensitivity of $100 \%$, a specificity of $37 \%$, a positive predictive value (PPV) of $37 \%$ and a negative predictive value (NPV) of 100\% for angiographic ARVD/C diagnosis (BrS group III). Late potentials were significantly more frequent at $40 \mathrm{~Hz}$ and at 40 and/or $25 \mathrm{~Hz}$ in $\mathrm{BrS}$ group III compared to patients with a BrS-ECG and no ARVD/C [BrS groups (I+II), $\chi^{2}$ test, $p=0.04$ and $p=0.02$ respectively, $p=0.06$ for $25 \mathrm{~Hz}$ alone].

\section{INVASIVE ELECTROPHYSIOLOGICAL STUDY (BrS GROUP)}

Mean HV interval was $48 \pm 7 \mathrm{~ms}$ (range 38-65 ms). Mean RV effective refractory period was $226 \pm 20 \mathrm{~ms}$. A sustained/syncopal VF or polymorphic VT was induced in $28 \%$ of the cases $(n=14)$, while non-sustained polymorphic VT was induced in 7 additional patients. We found no difference concerning inducibility between BrS groups I, II, and III, neither between asymptomatic and symptomatic patients, nor between patients with or without spontaneous type $1 \mathrm{BrS}-\mathrm{ECG}$. Finally, one of the 2 patients who experienced previous SCD was not inducible $(n=25)$.

\section{NON-INVASIVE IMAGING (BrS GROUP)}

Cardiac MRI was performed in 29 BrS patients. Overall, MRI abnormalities (mainly localized RV wall motion abnormalities) were seen in $45 \%(13 / 29)$ of BrS patients, with fatty infiltration in $17 \%(5 / 29)$, which was often considered as non-specific by radiologists.

Radionuclide angiography was performed in $32 \mathrm{BrS}$ patients. Mean RVEF was $52 \pm 7 \%$ and mean LVEF was $64 \pm 5 \%$ (versus contrast angiography, $p=N S$ and $p=0.03$, respectively). We noticed in $25 \%$ of the 32 explored cases $(n=8)$ a RVOT phase delay and a localized RV hypokinesia in $13 \%(n=4)$. Seven patients from BrS group III underwent angioscintigraphy, which confirmed in two cases the diagnosis of ARVD/C made with contrast angiography (marked localized hypokinesia associated with a RVOT phase delay). Despite a poor sensitivity for ARVD/C diagnosis, angioscintigraphy had an excellent PPV (100\%) and a good NPV (86\%) as compared to contrast angiography (Table 3, bottom). 


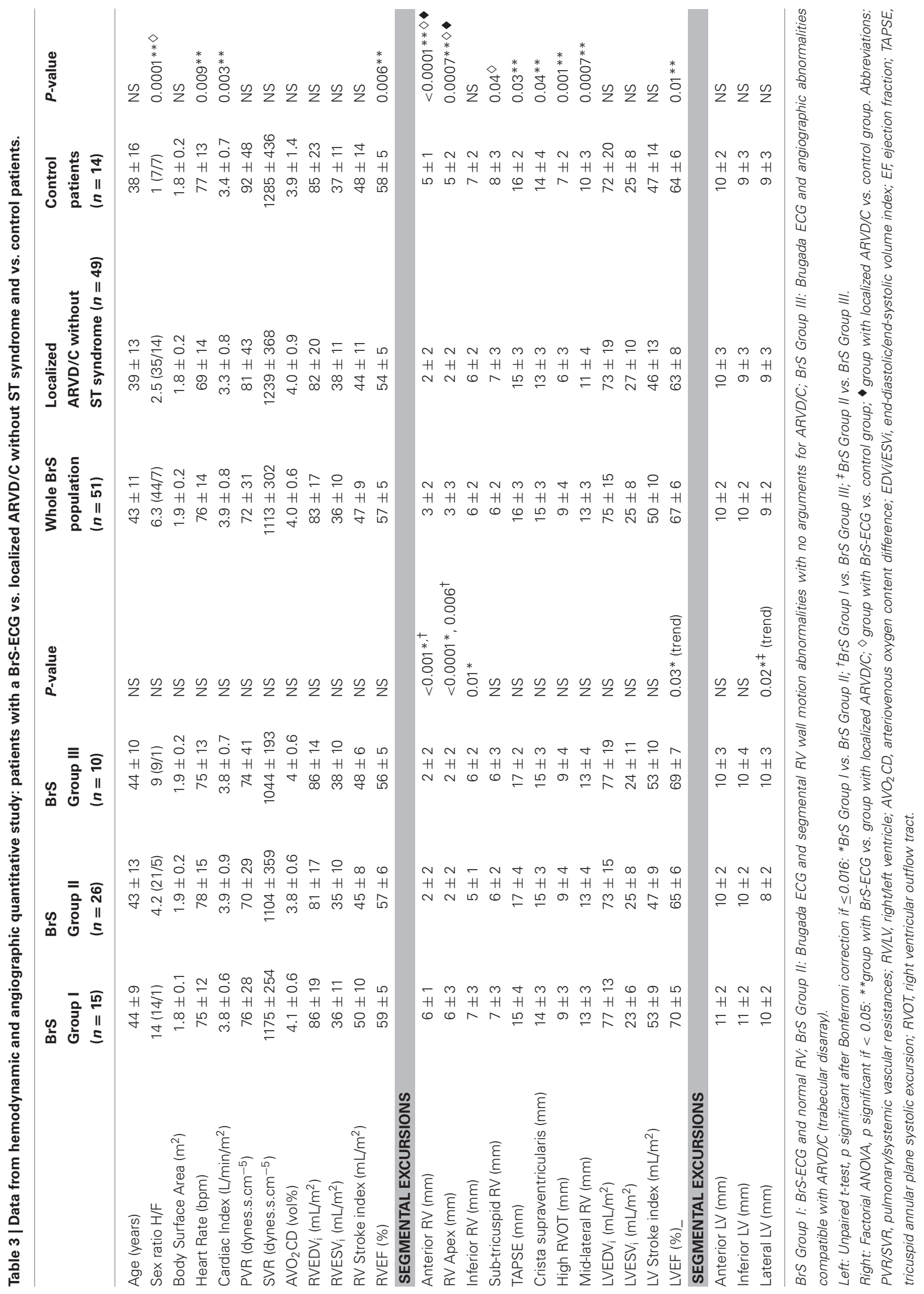




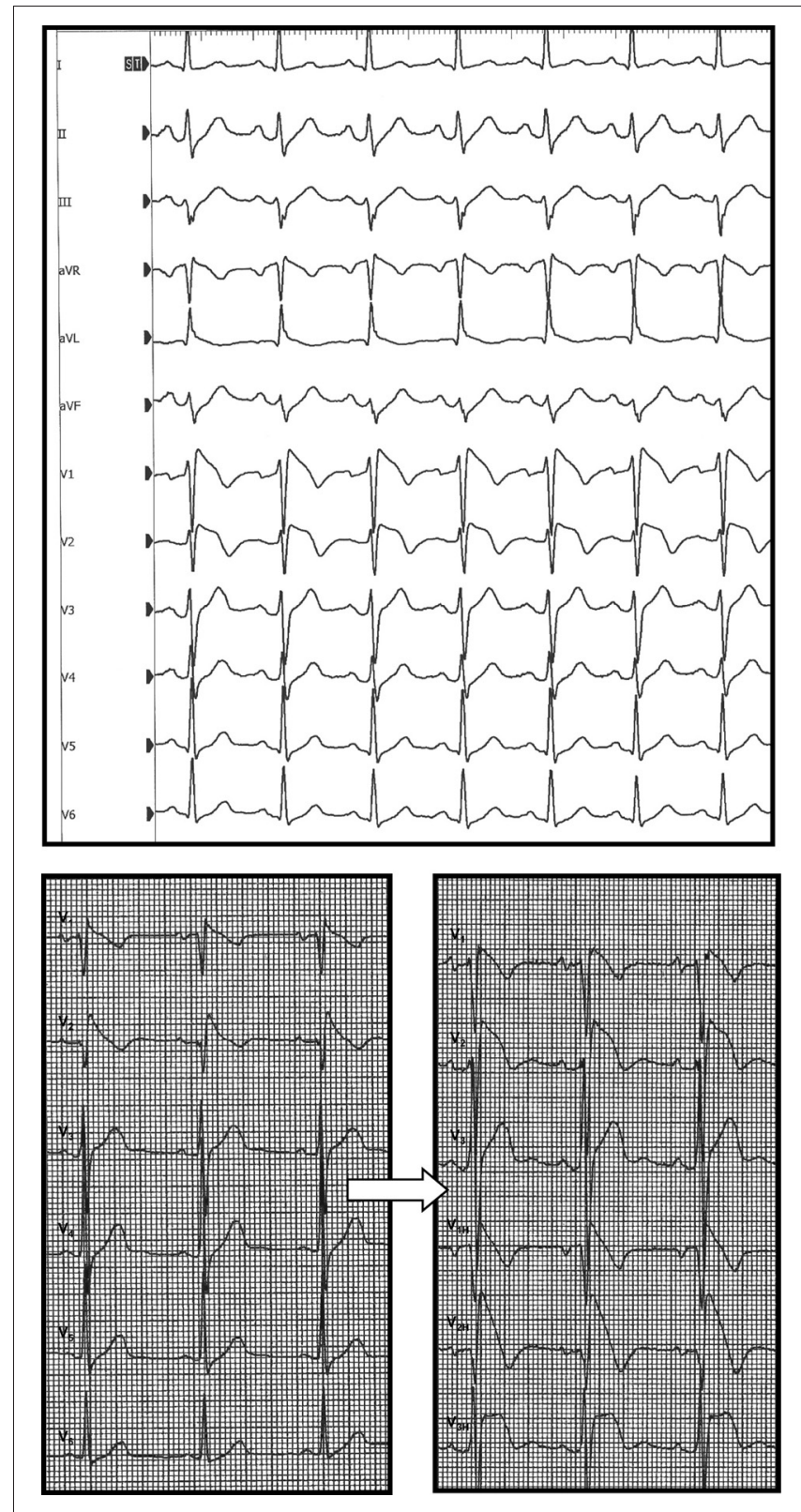

FIGURE 3 | Two typical BrS-ECGs (speed $25 \mathrm{~mm} / \mathrm{s}$; gain $1 \mathrm{~mm} / \mathrm{mV}$ ). Top: patient 33 with a baseline type 1 Brugada ECG (BrS group I). Bottom: patient 43 with a spontaneous type 1 Brugada ECG (left panel), becoming caricatural after ajmaline infusion (right panel, $\mathrm{BrS}$ group III, ARVD/C). $V_{1 \mathrm{H}}$, $V_{2 H}, V_{3 H}$ mean upper space above the right precordial leads $V_{1}, V_{2}$, and $V_{3}$, respectively.

\section{CARDIAC CATHETERIZATION}

\section{Hemodynamical study (Table 3)}

All groups under study were comparable in terms of right or left heart pressures, pulmonary or systemic vascular resistances (PVR, SVR), arteriovenous oxygen content difference, or hemoglobin content. The significant difference in heart rate observed between $\mathrm{BrS}$ group and patients with localized ARVD/C without ST segment elevation was attributed to the frequent prescription of $\beta$-blockers in the last group ( $76 \pm 14$ vs. $69 \pm 14 \mathrm{bpm}, p=$ 0.009). Cardiac index was significantly higher in patients from the BrS group compared to patients with localized ARVD/C without ST abnormalities $\left(3.9 \pm 0.8\right.$ vs. $3.3 \pm 0.8 \mathrm{~L} / \mathrm{min} / \mathrm{m}^{2}, p=$ 0.003). This was also the case when comparing BrS group III (ST-syndrome and ARVD/C) with localized ARVD/C without ST abnormalities $\left(3.9 \pm 0.7\right.$ vs. $\left.3.3 \pm 0.8 \mathrm{~L} / \mathrm{min} / \mathrm{m}^{2}, p=0.01\right)$. This finding could be also attributed to the lower heart-rate of this group. We observed no significant difference in terms of cardiac index between BrS groups I, II, III, and control patients.

\section{Digitized quantitative contrast angiography}

Qualitative analysis. The 26 patients from $\mathrm{BrS}$ group II (without overt structural abnormalities) had three different types of segmental wall motion abnormalities (Figure 4): (1) diffuse anterior RV hypokinesia or akinesia $(n=15)$, corresponding to an extended anteroapical RV hypokinesia, sometimes associated with an inferior RV hypokinesia $(n=9)$; (2) localized apical RV hypokinesia or akinesia $(n=7)$; and (3) hypokinesia or akinesia restricted to the anterior RV infundibulo-trabecular junction $(n=4)$. BrS group III patients $(n=10)$ had RV structural abnormalities (deep fissuring) corresponding to early or localized ARVD/C, predominantly affecting the RV anteroapical wall (Figures 1, 2).

LV anatomy was comparable between BrS groups I, II, and III. None of the patients had RV or LV microaneurysms (Frustaci et al., 2005).

Quantitative assessment of RV systolic function (Table 3). The RVEF and TAPSE were comparable between BrS groups I, II, and III, as well as between BrS group and control patients. However, RVEF was significantly higher in BrS group compared to ARVD/C patients without ST segment elevation ( $57 \pm 5$ vs. $54 \pm 5 \%, p=$ 0.006). This difference was related to a higher RVEF among patients with a BrS-ECG and no ARVD/C (BrS groups I+II, $n=$ 41) compared to ARVD/C patients without ST segment elevation ( $58 \pm 5$ vs. $54 \pm 5 \%, p=0.004$ ). RVEF was comparable between the BrS group III and ARVD/C patients without ST segment elevation ( $56 \pm 5$ vs. $54 \pm 5 \%, p=N S)$.

Statistically significant differences in terms of segmental excursion between BrS groups I, II and III were seen for the anterior, apical (BrS group I vs. II, BrS group I vs. III) and inferior (BrS group I vs. II) walls of the RV. On one hand, there was no difference in terms of RV segmental excursion between BrS groups II and III. On the other hand, only localized ARVD/C (with or without BrS-ECG) provided anteroapical dyskinesia. The excursion of the mid-lateral wall was significantly larger in patients with a BrS-ECG and no ARVD/C (BrS groups I+II), as compared to control patients and ARVD/C patients without ST segment elevation $(12.6 \pm 3.3$ vs. $10.3 \pm 3.0$ and $10.6 \pm 3.8 \mathrm{~mm}$, $p=0.02)$.

Quantitative assessment of $L V$ systolic function (Table 3). The LVEF was comparable between BrS groups I, II, and III, and between BrS group and control patients.

No complication occurred during follow-up. 


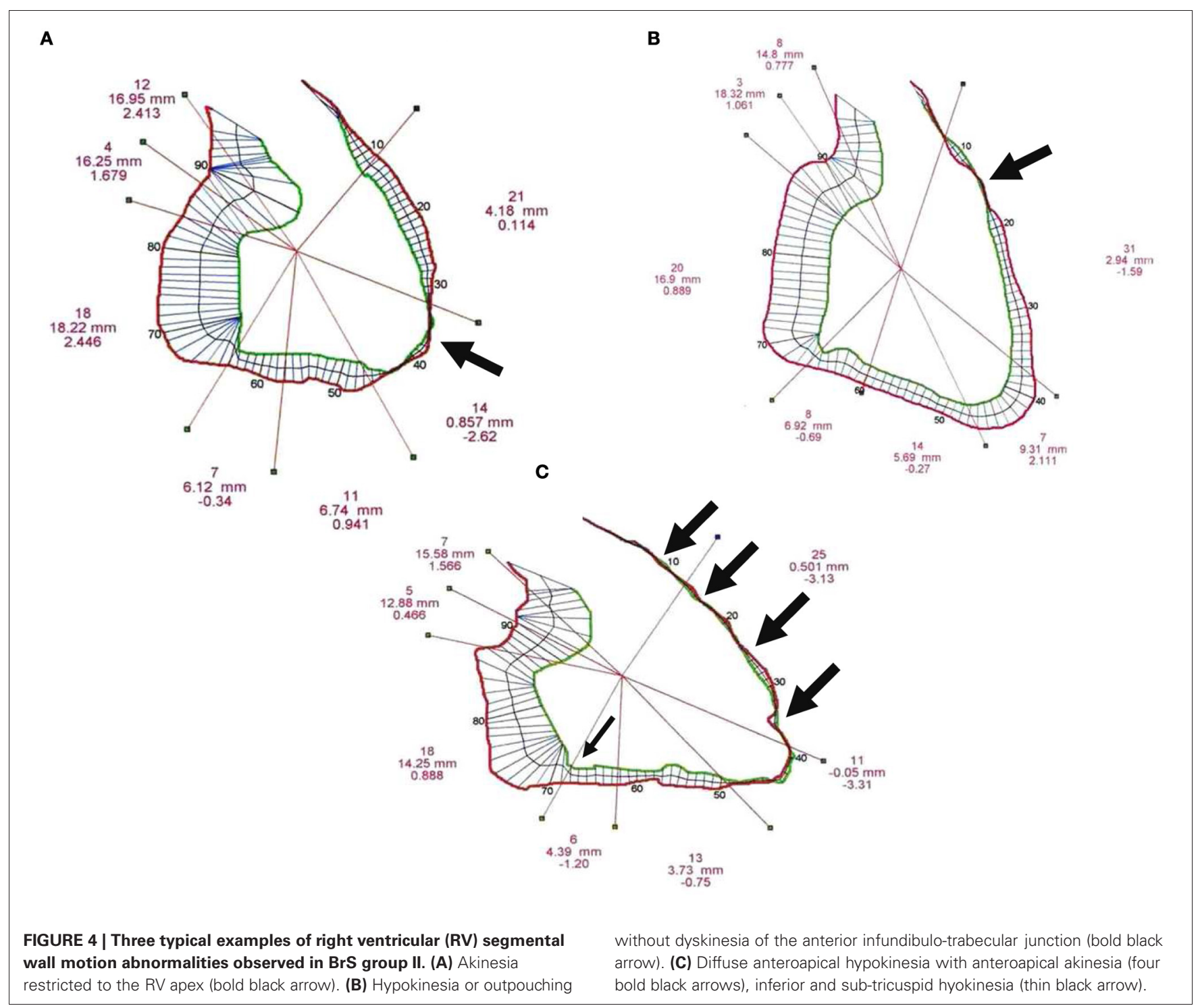

\section{GENETICS}

The results of our genetic study $(n=45)$ are reported in Tables 1, 2. A missense R965C SCN5A mutation was found in one patient (patient $41, \mathrm{BrS}$ group II), resulting in a single amino-acid substitution. A Black african male (patient 33) belonging to BrS group I carried an African SCN5A polymorphism (R481W) concerning a highly preserved gene segment among 5 species and 300 controls, which has been described in a recent publication as a special polymorphism (Tan et al., 2005). He had also a double polymorphism of DSG2 and DSC2. Patient 37, native of Cambodia, carried a TRPM4 mutation p.Q131H (c.393G $>$ C) and had a baseline incomplete right bundle branch block, associated with a type 3 BrS-ECG and a left anterior fascicular block.

Among the 10 patients from BrS group III who underwent a more extensive genetic study, no desmosomal gene mutation was found. Patient 43 carried a rare PKP2 polymorphism (missense, A264V) and patient 44 carried a DSG2 polymorphism (p.Ser882Pro, c2644T >C). No SCN5A mutation was found in this group (Table 2, bottom). Another PKP2 polymorphism was found in patient 24 (BrS group II).

\section{DISCUSSION}

BrS is an important cause of SCD among young people, particularly in men, like hypertrophic cardiomyopathy and ARVD/C [BrS represents 4 to $10 \%$ of all SCD and $20 \%$ of SCD with a normal heart (Antzelevitch et al., 2005)]. In their first report, Brugada and Brugada described eight cases without echocardiographic or angiographic abnormalities (Brugada and Brugada, 1992). In later studies however, the absence of structural abnormalities was presumed from routine echocardiography and MRI, which have a poor sensitivity for the diagnosis of focal ARVD/C, myocarditis (microaneurysms) or early stage of cardiomyopathy, all able to mimic a BrS (Frustaci et al., 2005). The main objective of the present study was to look for a potential overlap between $\mathrm{BrS}$ and ARVD/C by assessing prospectively their respective prevalence on the basis of international criteria, in patients with BrS-ECG and 
normal echocardiography. This question is important in daily practice when a patient is referred for BrS or BrS-ECG evaluation and management. Therapeutic options remain indeed challenging in the setting of a BrS-ECG pattern associated with ARVD/C as arrhythmias are usually triggered by exercise in ARVD/C and by vagal tone and rest in $\mathrm{BrS}$, but also because anti-arrhythmic drugs such as all $\mathrm{I}_{c}$ class (flecainide) and beta-blockers are protective in ARVD/C while contra-indicated (class $\mathrm{I}_{\mathrm{c}}$ ) or not logical in $\mathrm{BrS}$ (isoproterenol is useful for electrical storm management in BrS) (Postema et al., 2009).

\section{MAIN FINDINGS}

In our series, the primary endpoint was achieved in 4/51 patients $(8 \%)$ with a BrS-ECG who fulfilled both ESC/WHF 2000 ARVD/C criteria and HRS/EHRA 2005 BrS criteria, despite a normal echocardiography.

Among BrS group, 34/51 patients (67\%) fulfilled BrS HRS/EHRA 2005 criteria, and 8/51 (16\%) fulfilled ESC/WHF 2000 ARVD/C criteria. Contrast angiography showed RV wall motion abnormalities in 36/51 patients (71\%). Among these patients, 26 (51\%) had RV wall motion abnormalities without structural alterations (i.e., deep fissuring, BrS group II), and 10 (20\%) presented structural alterations compatible with localized (anteroapical and/or diaphragmatic) ARVD/C (BrS group III). Only $15(29 \%)$ patients had a strictly normal RV at angiography.

To our knowledge, this is the first study that showed prospectively an overlap between BrS and ARVD/C. This notion of an overlap may suggest that some patients of our series belonging to BrS group II (i.e., segmental wall motion abnormalities without ARVD/C) could present a potential or subclinical ARVD/C, as it is the case among BrS group III patients. In our opinion, three assumptions can be made to explain this overlap: (1) the existence of functional abnormalities of myocardial contraction due to impaired depolarization [i.e., late activation (Coronel et al., 2005; Nademanee et al., 2011) and incomplete right bundle branch block] and impaired repolarization associated with $\mathrm{BrS}$ [i.e., transmural voltage gradient due to loss of the epicardial action potential dome (Yan and Antzelevitch, 1999)]. This hypothesis could be applied in cases of diffuse RV hypokinesis (anteroapical and inferior) or in case of localized high RVOT (i.e., infundibulotrabecular junction) bulging seen on MRI or contrast angiography; (2) the second hypothesis relies on the fact that structural abnormalities (including fibrosis and fatty infiltration) have been reported in association with $\mathrm{BrS}$ and/or mutations in the cardiac sodium channel, as were able to demonstrate Coronel et al. (Coronel et al., 2005). This might be the case in the presence of segmental RV akinesia or concealed ARVD/C and could be attributed to an excitation failure of the myocardium, in particular epicardial; and (3) RV conduction disturbances observed in BrS may explain a delayed onset of RV contraction, besides increasing RV wall stress (current-to-load mismatch) which could be responsible of the RV structural abnormalities over time (Coronel et al., 2006; Hoogendijk et al., 2010).

\section{ELECTROPHYSIOLOGY}

Ajmaline testing is recognized as the best method to unmask BrSECG. Its sensitivity, although imperfect, ranges from 80 to $100 \%$ among series (Priori et al., 2000; Hong et al., 2004; Wolpert et al., 2005), which is far better than with flecainide acetate (68\%). For Hong et al. (Hong et al., 2004), ajmaline testing has a good sensitivity and PPV to identify SCN5A mutations (94.4 and 93.3\%, respectively), making us confident in the diagnosis of $\mathrm{BrS}$ in our series.

Late potentials were present in $73 \%$ of the patients (27/37) of our BrS series. These results are concordant with Kim et al. series (82\%) (Kim et al., 2006). Late potentials were present in 63\% (17/27) of patients without ARVD/C (groups I and II) and in 60\% $(12 / 20)$ of patients without ARVD/C and fulfilling HRS/EHRA diagnostic criteria for BrS. Their presence does not appear specific of BrS with RV segmental wall motion abnormalities or of an organic RV disease like ARVD/C. Late potentials on SA-ECG have been related to the presence of epicardial diastolic (late) potentials located to the anterior wall of the RVOT (Nagase et al., 2002). For Antzelevitch et al., their presence could be the functional consequence of an epicardial notch accentuation associated with a loss of the action potential's dome (Antzelevitch, 2002), but other authors (Coronel et al., 2005) have shown the presence of a delayed endocardial conduction through the RVOT, in the absence of a transmural gradient, but in the presence of localized interstitial fibrosis, i.e., organic. These observations support the hypothesis of an arrhythmogenic substrate located to the RVOT. Indeed, Nademanee et al. have demonstrated that the arrhythmic underlying electrophysiological mechanism in patients with BrS was delayed (>100 ms) depolarization over the anterior aspect of the RVOT epicardium, showing low voltage $(<1 \mathrm{mV})$, prolonged $(>130 \mathrm{~ms})$ and fractionated late potentials. Catheter ablation over this abnormal area resulted in normalization of the BrS-ECG and prevented further VT/VF recurrence (Nademanee et al., 2011). In our series, SA-ECG was useful to exclude the diagnosis of localized ARVD/C associated with a BrS-ECG, with a sensitivity of $100 \%$ and NPV of $100 \%$, despite poor specificity and PPV (at 40 and/or $25 \mathrm{~Hz}$, positive if $\geq 2$ criteria).

The low rate of inducible patients during PVS in our series (28\%), compared to previously published series reporting an inducibility ranging from 36 (Kim et al., 2006) to 67\% (Priori et al., 2000), can be explained by the broad proportion of paucisymptomatic patients in our series, but also by the poor sensitivity and reproducibility of this tool, which has been shown even in survivors of VF (Priori et al., 2000; Eckardt et al., 2005). The prognostic value of the PVS seems limited, particularly in patients at low or intermediate risk like in our series, since it is known that the association of a BrS type 1 ECG with a history of spontaneous syncope is the major determinant of prognosis in the BrS (Priori et al., 2000; Eckardt et al., 2005; Probst et al., 2010).

\section{CARDIAC IMAGING AND HEMODYNAMICS}

The presence of angiographic morphological abnormalities in $71 \%$ of cases in this series confirms the relevance of a biventricular invasive study as part of the initial assessment of $\mathrm{BrS}$, yet rarely achieved in this indication. Our results also emphasizes the inability of standard echocardiography to identify early stages of cardiomyopathies like localized ARVD/C, but also the 
limitations of cardiac MRI (Frustaci et al., 2005) or radionuclide angiography in these indications (false positives for MRI, lack of sensitivity for MRI and radionuclide angiography). However, Takagi et al. (Takagi et al., 2001) were the first to demonstrate in vivo morphological MRI abnormalities of the RV in BrS, showing hypokinesia, akinesia or localized aneurysms, which were present in $81 \%$ of cases. Recently, Catalano et al. found with MRI a high prevalence (50 vs. $17 \%$ for controls) of mild RV wall motion abnormalities among patient with BrS associated with a reduction in RVOT ejection fraction, an enlargement of the RV inflow diameter, and a mild increase in RVESV (not RVEDV) without fatty infiltration (Catalano et al., 2009). These data together with other observations support the fact that morphological and histological abnormalities are very common in $\mathrm{BrS}$ (Frustaci et al., 2005; Kim et al., 2006; Zumhagen et al., 2009). They may take the form of simple RV wall motion abnormalities, of moderate changes such as hypertrophy, mild fibrosis, and fatty infiltration, but also of genuine early or localized cardiomyopathies (documented by endocardial biopsies by Frustaci et al.), which may include ARVD/C, myocarditis or a latent form of cardiomyopathy.

With quantitative digitized contrast angiography, we confirmed in vivo the postmortem observations of Corrado et al. (Corrado et al., 1996, 2001) which showed that the clinical forms of ARVD/C associated with a Brugada ECG were exclusively localized or focal, affecting the antero-apical wall of the RV and taking the aspect of a predominantly fatty ARVD/C. Moreover, the hemodynamic profile of our patients and the functional angiographic analysis suggest that ARVD/C associated with a BrSECG may correspond to an earlier phase of ARVD/C disease as compared to localized forms of ARVD/C without ST segment elevation in the right precordial leads.

\section{GENETIC STUDY}

The prevalence of a SCN5A mutation in our series was particularly low $[2.2 \%$ in our series, as compared to $15-25 \%$ in the literature (Ackerman et al., 2011)]. This might be explained by the low prevalence of family history of BrS/SCD in our series (12/51, 23\%). However, BrS-ECG was well characterized. This could also be due to the fact that the population under study is made of patients with a BrS-ECG pattern, without evidence for an overt structural heart disease (on echocardiogram), but which may include early forms of cardiomyopathies like ARVD/C, myocarditis, both mimicking BrS-ECG, or pure BrS.

One patient was initially thought to have a R481W mutation that has proven to be retrospectively a rare African polymorphism. However, this particular polymorphism could be not benign as its presence induces in vitro sodium current altered electrophysiology. Tan et al. showed (Tan et al., 2005) that the R481W polymorphic channel found in Blacks and Hispanics produced a significantly slower sodium current recovery from inactivation in both splice variant backgrounds and increased slow inactivation in Q1077del background compared with wild-type. Also, R481W showed a significantly negative shift of inactivation midpoint in Q1077del background. Shifts of a similar magnitude have been reported for arrhythmia syndrome mutations and are thought to be pathogenic.
Candidate gene analysis for MOG1 was disappointing as no patient out of 41 screened carried a mutation, even if it has been showed that dominant-negative mutations in MOG1 can impair the trafficking of $\mathrm{Na}(\mathrm{v}) 1.5$ to the membrane, leading to $I_{\mathrm{Na}}$ reduction and clinical manifestation of BrS (Kattygnarath et al., 2011). The presence of a previously published TRPM4 mutation (patient 47, p.Q131H, c.393G >C) suggests a relationship between progressive conduction diseases and BrS (Stallmeyer et al., 2012).

Given our analysis of genes encoding proteins of the cardiac desmosome in patients with BrS and RV structural abnormalities compatible with ARVD/C, we would not recommend to test PKP2, DSP, DSG2, and DSC2 genes routinely in BrS. However, genetic testing is negative in $30-70 \%$ of overt forms of ARVD/C (Ackerman et al., 2011) and new candidate genes implicated in ARVD/C pathogenesis could be still good candidates for genetic screening in BrS. The absence of gene mutation in our patients with BrS-ECG and ARVD/C could also suggest the existence of a new entity, distinct from pure BrS and from ARVD/C itself, which could be genetic or acquired (such as myocarditis sequelae for example).

Our results underline the limited role of a systematic genetic screening in BrS and the debated causative role of SCN5A mutation in BrS (Coronel et al., 2006). Genetic testing has been recently recommended by HRS/EHRA experts for family members and appropriate relatives following the identification of the BrS-causative mutation in an index case; SCN5A mutation screening can be useful for any patient in whom a cardiologist has established a clinical index of suspicion for BrS; genetic testing is not indicated in the setting of an isolated type 2 or $3 \mathrm{BrS}$ ECG (Ackerman et al., 2011). Nevertheless, pathophysiology of $\mathrm{BrS}$ is complex and some authors as Coronel et al. and Frustaci et al. have reported three authentic SCN5A mutations associated with histological and/or angiographic findings consistent with ARVD/C in patients with BrS (Coronel et al., 2005; Frustaci et al., 2005), raising again the question of an overlap between $\mathrm{BrS}$ and localized forms ARVD/C (Perez Riera et al., 2005; Hoogendijk et al., 2010).

\section{STUDY LIMITATIONS}

Given that quantitative contrast angiography remains a goldstandard in ARVD/C, we do not currently have another available technique to assess the diagnostic accuracy of contrast angiography, apart from the histological examination of endomyocardial biopsies. These biopsies were not performed in the present series for safety reasons and for their poor diagnostic yield.

Genetic analysis was incomplete in this series as 6 patients without ARVD/C (6/41) refused genetic screening and as only 4 patients without ARVD/C underwent a finally negative screening of PKP2, DSP, DSG2, and DSC2 genes. Patients with ARVD/C and $\mathrm{BrS}$ may also present large genomic deletions, large insertions or genomic rearrangement, as we did not dispose at the time of the study of Multiplex Ligation-dependent Probe Amplification (MLPA) technique.

\section{CONCLUSIONS}

In our series, $71 \%$ of the 51 consecutive patients with a BrS-ECG and a normal echocardiography had abnormal RV wall motion 
and $16 \%$ had structural alterations corresponding to localized (anteroapical and/or diaphragmatic) ARVD/C at angiography. Moreover, $8 \%$ of patients with a BrS-ECG fulfilled both BrS and ARVD/C international criteria. Our results strongly support the hypothesis of an overlap between BrS and localized or concealed forms of ARVD/C, but also that Brugada ECG pattern is not specific of a pathophysiological entity, i.e., BrS, but can be due to other conditions such as myocarditis or localized RV cardiomyopathy.

In patients with such an overlap, and based on our experience, we would recommend to avoid Class Ic antiarrhythmic drugs prescription, automedication and fever (by the use of paracetamol or aspirin) as for any BrS patient. If ventricular arrhythmias are present, hydroquinidine and/or beta-blockers use could be considered, under careful ECG and Holter-ECG monitoring. ICD implantation indications should follow current available guidelines.

\section{REFERENCES}

Ackerman, M. J., Priori, S. G., Willems, S., Berul, C., Brugada, R., Calkins, H., et al. (2011). HRS/EHRA expert consensus statement on the state of genetic testing for the channelopathies and cardiomyopathies this document was developed as a partnership between the Heart Rhythm Society (HRS) and the European Heart Rhythm Association (EHRA). Heart Rhythm 8, 1308-1339.

Antzelevitch, C. (2002). Late potentials and the Brugada syndrome. J. Am. Coll. Cardiol. 39, 1996-1999.

Antzelevitch, C., Brugada, P., Borggrefe, M., Brugada, J., Brugada, R., Corrado, D., et al. (2005). Brugada syndrome: report of the second consensus conference: endorsed by the Heart Rhythm Society and the European Heart Rhythm Association. Circulation 111, 659-670.

Basso, C., Czarnowska, E., Della Barbera, M., Bauce, B., Beffagna, G., Wlodarska, E. K., et al. (2006). Ultrastructural evidence of intercalated disc remodelling in arrhythmogenic right ventricular cardiomyopathy: an electron microscopy investigation on endomyocardial biopsies. Eur. Heart J. 27, 1847-1854.

Breithardt, G., Cain, M. E., El-Sherif, N., Flowers, N. C., Hombach, V., Janse, M., et al. (1991). Standards for analysis of ventricular late potentials using high-resolution or signal-averaged electrocardiography. A statement by a Task Force Committee of the European Society of Cardiology, the American Heart Association, and the American College of Cardiology. Circulation 83, 1481-1488.

Brugada, P., and Brugada, J. (1992). Right bundle branch block, persistent ST segment elevation and sudden cardiac death: a distinct clinical and electrocardiographic syndrome. A multicenter report. J. Am. Coll. Cardiol. 20, 1391-1396.

Catalano, O., Antonaci, S., Moro, G., Mussida, M., Frascaroli, M., Baldi, M., et al. (2009). Magnetic resonance investigations in Brugada syndrome reveal unexpectedly high rate of structural abnormalities. Eur. Heart J. 30, 2241-2248.

Chen, Q., Kirsch, G. E., Zhang, D., Brugada, R., Brugada, J., Brugada, P., et al. (1998). Genetic basis and molecular mechanism for idiopathic ventricular fibrillation. Nature 392, 293-296.

Coronel, R., Berecki, G., and Opthof, T. (2006). Why the Brugada syndrome is not yet a disease: syndromes, diseases, and genetic causality. Cardiovasc. Res. 72, 361-363.

Coronel, R., Casini, S., Koopmann, T. T., Wilms-Schopman, F. J., Verkerk, A. O., De Groot, J. R., et al. (2005). Right ventricular fibrosis and conduction delay in a patient with clinical signs of Brugada syndrome: a combined electrophysiological, genetic, histopathologic, and computational study. Circulation 112, 2769-2777.

Corrado, D., Basso, C., Buja, G., Nava, A., Rossi, L., and Thiene, G. (2001). Right bundle branch block, right precordial st-segment elevation, and sudden death in young people. Circulation 103, 710-717.

Corrado, D., Fontaine, G., Marcus, F. I., McKenna, W. J., Nava, A., Thiene, G., et al. (2000).

We believe that a BrS ECG pattern may be an indicator of ARVC, particularly in its clinically concealed phase, thus requiring morphological RV evaluation, such as MRI, contrast echocardiography and/or contrast angiography. One of the explanations of the low prevalence of SCN5A mutations in our series may lie in the high proportion of structural abnormalities and of localized ARVD/C. Several reasons may explain that difference as compared to other series: (1) most of the Brugada series did not assess the RV morphology with more than a standard echocardiogram, which is of particularly limited interest for RV study; (2) very few authors performed digitized contrast angiography in BrS; and (3) among the 10 patients who happened to have RV morphological abnormalities compatible with ARVD/C, none presented a desmosomal mutation, which is atypical. This overlap between $\mathrm{BrS}$ and ARVD/C does not mean that these two diseases are the same one, but that a substantial proportion of patients with a Brugada ECG pattern present RV structural alterations.

Arrhythmogenic right ventricular dysplasia/cardiomyopathy: need for an international registry. Study Group on Arrhythmogenic Right Ventricular Dysplasia/Cardiomyopathy of the Working Groups on Myocardial and Pericardial Disease and Arrhythmias of the European Society of Cardiology and of the Scientific Council on Cardiomyopathies of the World Heart Federation. Circulation 101, E101-E106.

Corrado, D., Nava, A., Buja, G., Martini, B., Fasoli, G., Oselladore, L., et al. (1996). Familial cardiomyopathy underlies syndrome of right bundle branch block, STsegment elevation and sudden death. J. Am. Coll. Cardiol. 27, 443-448.

Corrado, D., and Thiene, G. (2006). Arrhythmogenic right ventricular cardiomyopathy/dysplasia: clinical impact of molecular genetic studies. Circulation 113, 1634-1637.

Eckardt, L., Probst, V., Smits, J. P., Bahr, E. S., Wolpert, C., Schimpf, R., et al. (2005). Long-term prognosis of individuals with right precordial ST-segment-elevation Brugada syndrome. Circulation 111, 257-263.

Frustaci, A., Priori, S. G., Pieroni, M., Chimenti, C., Napolitano, C., Rivolta, I., et al. (2005). Cardiac histological substrate in patients with clinical phenotype of Brugada syndrome. Circulation 112, 3680-3687.

Gomes, J. A., Winters, S. L., Stewart, D., Targonski, A., and Barreca, P. (1987). Optimal bandpass filters for time-domain analysis of the signalaveraged electrocardiogram. Am. J. Cardiol. 60, 1290-1298.

Hamid, M. S., Norman, M., Quraishi, A., Firoozi, S., Thaman, R., Gimeno,
J. R., et al. (2002). Prospective evaluation of relatives for familial arrhythmogenic right ventricular cardiomyopathy/dysplasia reveals a need to broaden diagnostic criteria. J. Am. Coll. Cardiol. 40, 1445-1450.

Hébert, J. L., Chemla, D., Gerard, O., Zamani, K., Quillard, J., Azarine, A., et al. (2004). Angiographic right and left ventricular function in arrhythmogenic right ventricular dysplasia. Am. J. Cardiol. 93, 728-733.

Hong, K., Brugada, J., Oliva, A., Berruezo-Sanchez, A., Potenza, D., Pollevick, G. D., et al. (2004). Value of electrocardiographic parameters and ajmaline test in the diagnosis of Brugada syndrome caused by SCN5A mutations. Circulation 110, 3023-3027.

Hoogendijk, M. G., Opthof, T., Postema, P. G., Wilde, A. A., De Bakker, J. M., and Coronel, R. (2010). The Brugada ECG pattern: a marker of channelopathy, structural heart disease, or neither? Toward a unifying mechanism of the Brugada syndrome. Circ. Arrhythm. Electrophysiol. 3, 283-290.

Kattygnarath, D., Maugenre, S., Neyroud, N., Balse, E., Ichai, C., Denjoy, I., et al. (2011). MOG1: a new susceptibility gene for Brugada syndrome. Circ. Cardiovasc. Genet. 4, 261-268.

Kim, H., Cho, Y., Park, Y., Lee H., Kang, H., Nah, D. Y., et al. (2006). Underlying cardiomyopathy in patients with ST-segment elevation in the right precordial leads. Circ. J. 70, 719-725.

Marcus, F. I., Fontaine, G. H., Guiraudon, G., Frank, R., Laurenceau, J. L., Malergue, C., et al. (1982). Right ventricular 
dysplasia: a report of 24 adult cases. Circulation 65, 384-398.

Martini, B., Nava, A., Thiene, G., Buja, G. F., Canciani, B., Scognamiglio, R., et al. (1989). Ventricular fibrillation without apparent heart disease: description of six cases. Am. Heart J. 118, 1203-1209.

McKenna, W. J., Thiene, G., Nava, A., Fontaliran, F., BlomstromLundqvist, C., Fontaine, G., et al. (1994). Diagnosis of arrhythmogenic right ventricular dysplasia/cardiomyopathy. Task Force of the Working Group Myocardial and Pericardial Disease of the European Society of Cardiology and of the Scientific Council on Cardiomyopathies of the International Society and Federation of Cardiology. Br. Heart J. 71, 215-218.

Nademanee, K., Veerakul, G., Chandanamattha, P., Chaothawee, L., Ariyachaipanich, A., Jirasirirojanakorn, K., et al. (2011). Prevention of ventricular fibrillation episodes in Brugada syndrome by catheter ablation over the anterior right ventricular outflow tract epicardium. Circulation 123, 1270-1279.

Nagase, S., Kusano, K. F., Morita, H., Fujimoto, Y., Kakishita, M., Nakamura, K., et al. (2002). Epicardial electrogram of the right ventricular outflow tract in patients with the Brugada syndrome: using the epicardial lead. J. Am. Coll. Cardiol. 39, 1992-1995.

Papavassiliu, T., Wolpert, C., Fluchter, S., Schimpf, R., Neff, W., Haase, K. K., et al. (2004). Magnetic resonance imaging findings in patients with Brugada syndrome. J. Cardiovasc. Electrophysiol. 15, 1133-1138.

Perez Riera, A. R., Antzelevitch, C., Schapacknik, E., Dubner, S., and Ferreira, C. (2005). Is there an overlap between Brugada syndrome and arrhythmogenic right ventricular cardiomyopathy/dysplasia? J. Electrocardiol. 38, 260-263.
Peters, S., Trummel, M., Denecke, S., and Koehler, B. (2004). Results of ajmaline testing in patients with arrhythmogenic right ventricular dysplasia-cardiomyopathy. Int. J. Cardiol. 95, 207-210.

Pilichou, K., Nava, A., Basso, C., Beffagna, G., Bauce, B., Lorenzon, A., et al. (2006). Mutations in desmoglein-2 gene are associated with arrhythmogenic right ventricular cardiomyopathy. Circulation 113, 1171-1179.

Postema, P. G., Wolpert, C., Amin, A. S., Probst, V., Borggrefe, M., Roden, D. M., et al. (2009). Drugs and Brugada syndrome patients: review of the literature, recommendations, and an up-to-date website (www.brugadadrugs.org). Heart Rhythm 6, 1335-1341.

Priori, S. G., Napolitano, C., Gasparini, M., Pappone, C., Della Bella, P., Brignole, M., et al. (2000). Clinical and genetic heterogeneity of right bundle branch block and ST-segment elevation syndrome: a prospective evaluation of 52 families. Circulation 102, 2509-2515.

Priori, S. G., Napolitano, C., Gasparini, M., Pappone, C., Della Bella, P., Giordano, U., et al. (2002). Natural history of Brugada syndrome: insights for risk stratification and management. Circulation 105, 1342-1347.

Probst, V., Veltmann, C., Eckardt, L., Meregalli, P. G., Gaita, F., Tan, H. L., et al. (2010). Long-term prognosis of patients diagnosed with Brugada syndrome: results from the FINGER Brugada Syndrome Registry. Circulation 121, 635-643.

Sen-Chowdhry, S., Syrris, P., and McKenna, W. J. (2007a). Role of genetic analysis in the management of patients with arrhythmogenic right ventricular dysplasia/cardiomyopathy. J. Am. Coll. Cardiol. 50, 1813-1821.

Sen-Chowdhry, S., Syrris, P., Ward, D., Asimaki, A., Sevdalis, E., and McKenna, W. J. (2007b). Clinical and genetic characterization of families with arrhythmogenic right ventricular dysplasia/cardiomyopathy provides novel insights into patterns of disease expression. Circulation 115, 1710-1720.

Stallmeyer, B., Zumhagen, S., Denjoy, I., Duthoit, G., Hebert, J. L., Ferrer X., et al. (2012). Mutational spectrum in the $\mathrm{Ca}(2+)$-activated cation channel gene TRPM4 in patients with cardiac conductance disturbances. Hum. Mutat. 33, 109-117.

Takagi, M., Aihara, N., Kuribayashi, S., Taguchi, A., Shimizu, W., Kurita, T., et al. (2001). Localized right ventricular morphological abnormalities detected by electron-beam computed tomography represent arrhythmogenic substrates in patients with the Brugada syndrome. Eur. Heart J. 22, 1032-1041.

Tan, B. H., Valdivia, C. R., Rok, B. A., Ye, B., Ruwaldt, K. M., Tester, D. J., et al. (2005). Common human SCN5A polymorphisms have altered electrophysiology when expressed in Q1077 splice variants. Heart Rhythm 2, 741-747.

Van Tintelen, J. P., Entius, M. M., Bhuiyan, Z. A., Jongbloed, R. Wiesfeld, A. C., Wilde, A. A., et al (2006). Plakophilin-2 mutations are the major determinant of familial arrhythmogenic right ventricular dysplasia/cardiomyopathy Circulation 113, 1650-1658.

Wilde, A. A., Antzelevitch, C. Borggrefe, M., Brugada, J., Brugada, R., Brugada, P., et al. (2002). Proposed diagnostic criteria for the Brugada syndrome: consensus report. Circulation 106, 2514-2519.

Wolpert, C., Echternach, C., Veltmann, C., Antzelevitch, C., Thomas, G. P. Spehl, S., et al. (2005). Intravenous drug challenge using flecainide and ajmaline in patients with Brugada syndrome. Heart Rhythm 2, 254-260.
Yan, G. X., and Antzelevitch, C. (1999). Cellular basis for the Brugada syndrome and other mechanisms of arrhythmogenesis associated with ST-segment elevation. Circulation 100, 1660-1666.

Zumhagen, S., Spieker, T., Rolinck, J., Baba, H. A., Breithardt, G., Bocker, W., et al. (2009). Absence of pathognomonic or inflammatory patterns in cardiac biopsies from patients with Brugada syndrome. Circ. Arrhythm. Electrophysiol. 2, $16-23$

Conflict of Interest Statement: The authors declare that the research was conducted in the absence of any commercial or financial relationships that could be construed as a potential conflict of interest.

Received: 24 February 2012; accepted: 04 December 2012; published online: 27 December 2012.

Citation: Duthoit G, Fressart V, HiddenLucet $F$, Simon $F$, Kattygnarath $D$, Charron P, Himbert C, Aouate P, Guicheney P, Lecarpentier Y, Frank $R$ and Hébert J-L (2012) Brugada ECG pattern: a physiopathological prospective study based on clinical, electrophysiological, angiographic, and genetic findings. Front. Physio. 3:474. doi: 10.3389/fphys. 2012.00474

This article was submitted to Frontiers in Cardiac Electrophysiology, a specialty of Frontiers in Physiology.

Copyright (c) 2012 Duthoit, Fressart, Hidden-Lucet, Simon, Kattygnarath, Charron, Himbert, Aouate, Guicheney, Lecarpentier, Frank and Hébert. This is an open-access article distributed under the terms of the Creative Commons Attribution License, which permits use, distribution and reproduction in other forums, provided the original authors and source are credited and subject to any copyright notices concerning any third-party graphics etc. 